\title{
DROUGHT TOLERANCE OF EUROPEAN BARLEY (HORDEUM VULGARE L.) VARIETIES
}

\author{
ILDIKÓ SCHMIDTHOFFER ${ }^{1}$, LÁSZLÓ SZILÁK ${ }^{1}$, PÉTER MOLNÁR ${ }^{1}$, PÉTER CSONTOS ${ }^{2 *}$, \\ ANNA SKRIBANEK ${ }^{1}$
}

'Eötvös Loránd University, Szombathely, Hungary

${ }^{2}$ Institute for Soil Science and Agricultural Chemistry, Centre for Agricultural Research, Hungarian Academy of Sciences, Budapest, Hungary

SCHMIDTHOFFER, I. - SZILÁK, L. - MOLNÁR, P. - CSONTOS, P. - SKRIBANEK, A: Drought tolerance of European barley (Hordeum vulgare L.) varieties. Agriculture (Pol’nohospodárstvo), vol. 64, 2018, no. 3, pp. $137-142$.

\begin{abstract}
Drought is one of the major abiotic stresses that frequently causes severe loss in crop yield worldwide. Laboratory predictors of field drought tolerance could significantly increase the effectiveness of existing plant breeding programs. In earlier field experiments, drought tolerance of 22 cultivated barley varieties has already been quantified. In order to develop laboratory markers of drought sensitivity, field drought tolerance data were correlated with parameters obtained in laboratory tests. Root and shoot length and weight were measured on control and PEG-treated (a simple laboratory drought model) seedlings. Significant correlations were found among root growth, shoot weight in laboratory stress conditions and field drought tolerance. Interestingly, a negative correlation was found between root length of the untreated seedlings and drought tolerance. Laboratory Drought Tolerance Index (DTI) was introduced as the linear combination of those laboratory parameters which were correlated with field drought tolerance. DTI showed good predictive value $(r=0.57, p<0.05)$ for drought tolerance in field experiments and we suggest it for preselection of drought tolerant barley breeding lines and for the characterization of drought tolerance in general.
\end{abstract}

Key words: drought tolerance index, Hordeum vulgare L., PEG treatment, plant breeding

Malting barley is especially sensitive for drought conditions (Samarah 2005) and the crop production is already negatively impacted by the global warming trends (Lobell \& Field 2007). Therefore, development of new drought tolerant barley varieties has high economic importance. Discovery of new physiological markers which are associated with drought tolerant phenotypes would significantly accelerate the usually slow breeding process (Stuber et al. 1999).
In the field, there are negative consequences of drought on the physiological development and growth of plants; the most important among them is a decrease in crop yield (Anjum et al. 2011; Chaves et al. 2003). In the laboratory it is not practical to wait until the full development of the plants, thus, other measures than crop yield should be used for the characterization of drought sensitivity. Several drought tests have been developed for different

Ildikó Schmidthoffer, pre-doctor (PhD. student), Department of Biology, Eötvös Loránd University, Károlyi Gáspár tér 4., Szombathely, H-9700, Hungary. E-mail: keri.schmidthoffer.ildiko@sek.elte.huy

László Szilák, assistant professor, Department of Biology, Eötvös Loránd University, Károlyi Gáspár tér 4., Szombathely, H-9700, Hungary. E-mail: laszlo.szilak@gmail.com

Péter Molnár, assistant professor, Department of Biology, Eötvös Loránd University, Károlyi Gáspár tér 4., Szombathely, H-9700, Hungary. E-mail: molnarp65@gmail.com

Dr. habil. Péter Csontos, PhD., DSc. (*Corresponding author), senior research fellow, Institute for Soil Science and Agricultural Chemistry, Centre for Agricultural Research, Hungarian Academy of Sciences, Herman Ottó út 15, Budapest, H-1022, Hungary. E-mail: cspeter@mail.iif.hu

Dr. habil. Anna Skribanek, PhD., assistant professor, Department of Biology, Eötvös Loránd University, Károlyi Gáspár tér 4., Szombathely, H-9700, Hungary. E-mail: skribanek.anna@sek.elte.hu 
applications and for different growth stage of the plants. Dehydrating polyethylene glycol (PEG) treatment is frequently used to model drought conditions in seedlings (Pei et al. 2010; Hamayun et al. 2010). Several physiological parameters have already been indicated to be associated with drought tolerance in the field and also in the laboratory (Ashraf 2010; Fleury et al. 2010). The inhibition of the growth of the roots and stems (Frensch 1997; Munns 2002), a decrease in the number of shoots (Cone et al. 1995) and a reduction in the assimilating leaf area (Passioura 1988) could be observed even after moderate water deficit resulting in a significant yield loss.

Hunt for new physiological markers should be in the focus of the plant breeders, because it can accelerate the selection and characterization of the breeding stocks. In this study we used common barley varieties cultivated in Hungary and the neighboring countries with known field drought tolerance, we selected a simple and fast dehydration model on seedlings (PEG treatment), a low number of physiological parameters and created an effective laboratory predictor for drought tolerance in the field.

For the laboratory evaluation of the effects of drought on the physiological parameters of 9
Hungarian and 13 further European barley (Hordeum vulgare $\mathrm{L}$.) varieties, 30-30 grains were germinated between wet filter papers at $22^{\circ} \mathrm{C}$ for 2 days, then placed on germination racks in liquid culture medium (25\% Hoogland) under natural lighting conditions. Eight-day-old seedlings were kept in 20\% PEG6000 solution for 48 hours (drought stress) then root and shoot length and weight were measured in 10-10 seedlings in 4 replicates and compared to non-treated seedlings kept in liquid culture medium without PEG.

Pearson's correlation analysis and multiple linear regression were used for statistical analysis with the help of the Past statistical software (Hammer et al. 2001).

Dehydrating PEG treatment, applied between the $8^{\text {th }}$ and the $10^{\text {th }}$ days of culture, resulted in decrease all of the growth parameters compared to the controls. The average retardation of the leaf and root length, and also the root weight, was relatively small but significant (at $p<0.05$ level) (root length: $-8 \%$, control $=8.43 \pm 0.19, \mathrm{PEG}=7.71 \pm 0.14 \mathrm{~cm}$; leaf length: $-11.4 \%$, control $=17.71 \pm 0.13$, PEG $=15.69 \pm 0.11 \mathrm{~cm}$; root weight: $-10.4 \%$, control $=$ $0.77 \pm 0.05, \mathrm{PEG}=0.69 \pm 0,04 \mathrm{~g}$ fresh weight $/ 10 \mathrm{piec}-$ es (pcs)), whereas the average weight of the stressed

$\mathrm{T}$ a b 1 e 1

Drought tolerance of European barley varieties in the field

\begin{tabular}{|c|c|c|c|}
\hline Breed & $\begin{array}{c}\text { Field drought tolerance } \\
{[\%]}\end{array}$ & Breed & $\begin{array}{c}\text { Field drought tolerance } \\
{[\%]}\end{array}$ \\
\hline Mandolina & 25.4 & Explorer & -1.9 \\
GK Habzó & 18.8 & Tatum & -7.9 \\
Marthe & 17.4 & Tocada & -8.1 \\
GKS 9413 & 14.5 & Bojos & -9.1 \\
KH Andrea & 12.2 & Quench & -14.1 \\
GKS 903 & 7.6 & KH Lédi & -14.7 \\
GKS 902 & 5.2 & Grace & -15.8 \\
Chill & 3.6 & KH Szinva & -18.7 \\
Pasadena & 3.3 & KH Lilla & -20.0 \\
Xanadu & 2.3 & Mauritia & - \\
Scarlett & 2.3 & - & - \\
GKS 901 & 0.8 & - & - \\
\hline
\end{tabular}

Legend: Drought tolerance was measured according to the bioassay method developed by Cooper and Fox (1996) for the detection of environmental stress. Small-plot field experiments were performed in 9 different environments in Hungary. Field drought tolerance was quantified as crop yield differences between the more arid Eastern and the more humid Western crop growing regions (divided by average and expressed as percentage) (Tomcsányi 2012). 
plant leaves decreased in a higher extent $(-27.8 \%$, control $=1.69 \pm 0.06, \mathrm{PEG}=1.22 \mathrm{~g} / 10 \mathrm{pcs}, p<0.01)$.

Field drought tolerance of the barley varieties, based on earlier studies are shown in Table 1, and were used in the evaluation of our laboratory experiments. The predictive value of the parameters measured in the laboratory stress test for drought tolerance was estimated by calculating their correlation with the drought tolerance parameter obtained in field experiments. In the correlation table not only the absolute values of the parameters in the control and PEG treated groups, but their changes due to the treatment in absolute and also in percentage values were included. Only those parameters were considered further where significant $(p<0.05)$ correlation were found.

Retardation in root length caused by PEG treatment correlated well with drought tolerance in the field experiments (Figure 1). Interestingly, root length not only in the stressed but also in the untreated group showed a significant (negative) correlation with drought tolerance (control: $r=-0.44$, $p<0.05$; PEG: $r=-0.50, p<0.05$ ), which means that initial rapid root growth (rooting vigor) could

A

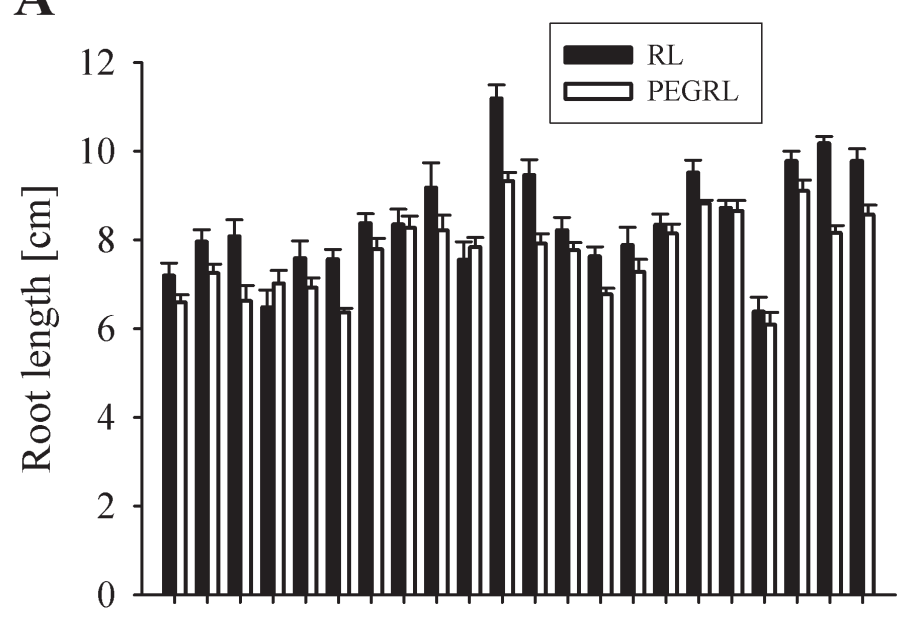

B
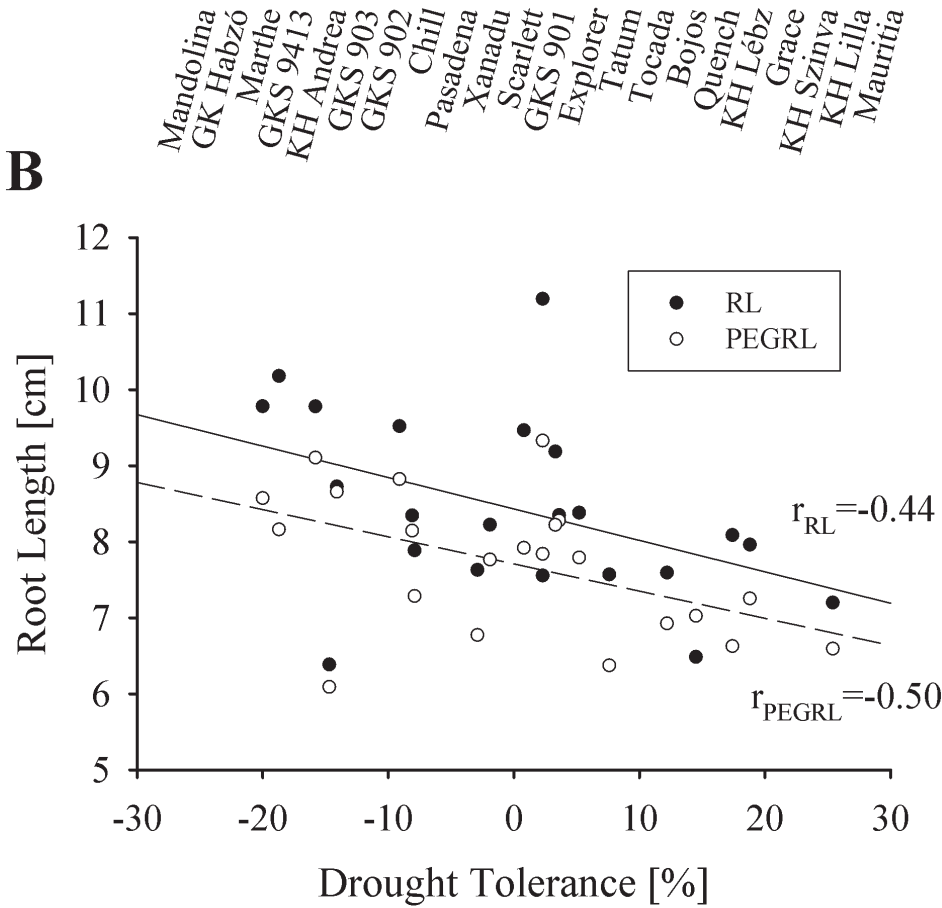

Figure 1. Effect of dehydrating stress treatment on root length (A) and correlation of root length with field drought tolerance (B) RL - Root length; PEGRL - Root length after PEG treatment 
be a disadvantage in the long-term compared to the slower growing breeds, because barley varieties with shorter roots had better drought tolerance in our experiments.

The initial intensive growth of leaf mass did not seem to influence drought tolerance, but breeds showing a smaller reduction in leaf mass upon dehydration treatment had higher drought tolerance $(r=-0.53, p<0.05$, Figure 2).

The highest correlation coefficient between the physiological parameters and field drought tolerance was about 0.53 . To achieve a higher predictive value we combined those parameters which showed significant correlation with field drought tolerance into one single parameter called Drought Tolerance Index. The following parameters were used: Root length after PEG treatment (Figure 1), Leaf weight after PEG treatment (Figure 2). The parameters were standardized using the following equation:

$$
\mathrm{x}^{\prime}=\left(\mathrm{x}-\mathrm{x}_{\text {mean }}\right) / \mathrm{s}_{\mathrm{x}}
$$

Multiple linear regression was performed with field drought tolerance as the dependent and the above parameters as the independent parameters.
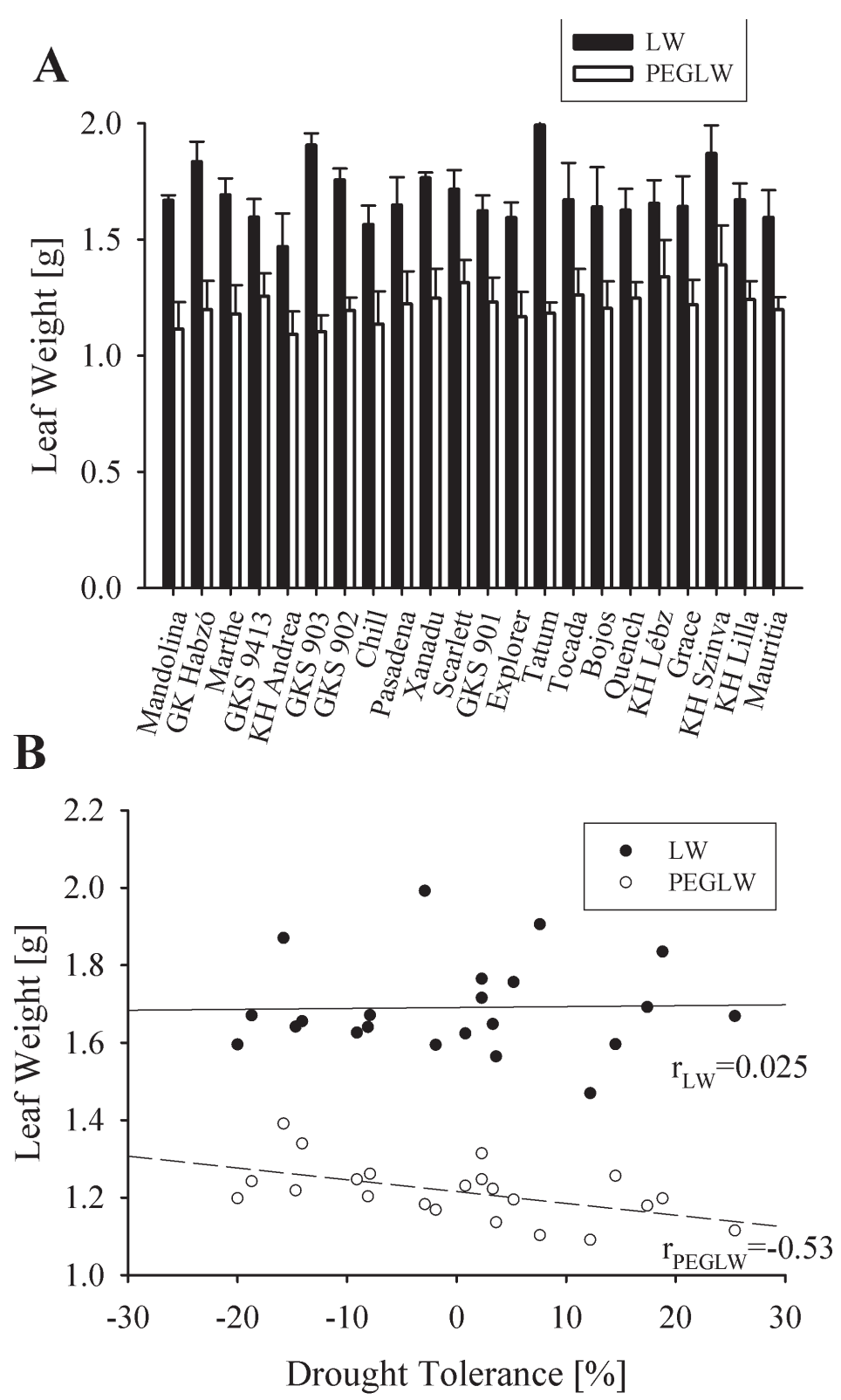

Figure 2. Effect of dehydrating stress treatment on leaf weight (A) and correlation of leaf weight with field drought tolerance (B) LW - Leaf Weight; PEGLW - Leaf Weight after PEG treatment 
Drought Tolerance Index (DTI) was calculated based on the obtained regression parameters (DTI $=-0.268 \times$ PEGRL $-0.362 \times$ PEGLW). Significant correlation $(r=0.57, p<0.05)$ was obtained between DTI and field drought tolerance (Figure 3). The drought tolerant and drought sensitive barley varieties were clearly separated (Figure 3 ).

Drought tolerance of commercially available barley varieties has already been published based on small plot field experiments in arid and humid environments (Tomcsányi 2012). Earlier, we published changes in photosynthetic activity of barley varieties upon laboratory drought stress (Skribanek et al. 2016). All three measured parameters, photosynthetic efficiency, yield and non-photochemical quenching decreased significantly upon drought conditions. In this series of experiments we studied other growth-connected physiological and biochemical parameters which could be used for the early, laboratory prediction of drought tolerance.

Dehydrating PEG6000 treatment is a commonly used method to simulate drought conditions in the laboratory. The found negative correlation between root length in the control and also in the PEG treated group and field drought tolerance is surprising but it is in good agreement with the results of Frensch
(1997) and Munns (2002), they reported that growth of roots and shoots are inhibited upon dehydration. In contrast, Schachtman and Goodger (2008) obtained contradictory data and hypothesized that one of the drought adaptation strategy of plants is the development of deep-penetrating thick root system for the compensation of shortage of water. One possible explanation for the conflicting data could be the different extent and timing of drought stress (i.e. short strong versus long mild water deprivation). In our experiments leaf weight in the PEG treated group showed the highest (although negative) correlation with field drought tolerance. None of one single physiological parameter had a sufficiently good predictive value for field drought tolerance, therefore we developed a combined Drought Tolerance Index (DTI) which included those parameters (root length and leaf weight after PEG treatment) which showed significant correlation with field drought tolerance and were relatively independent from each other. This combined parameter had a higher predictive value for field drought tolerance than any of the single parameters and seemed to be a satisfactory predictor for the selection of more drought tolerant barley varieties. The drought sensitive and tolerant barley varieties separated clearly on the basis of

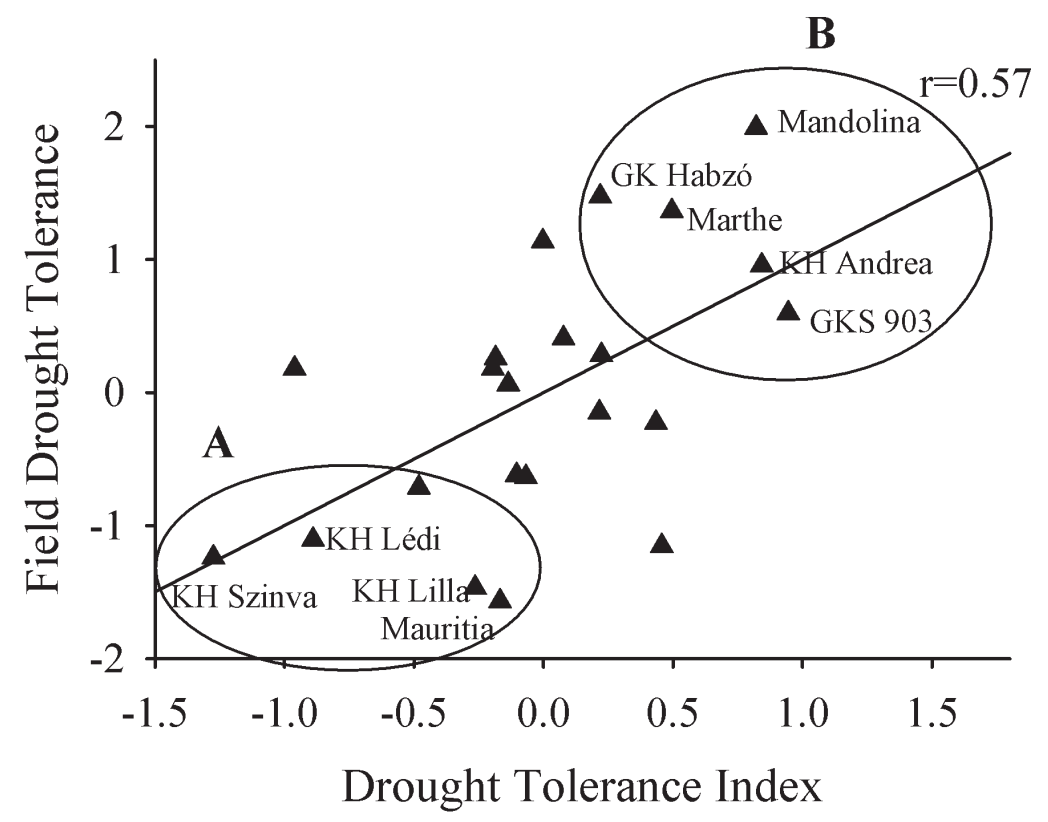

Figure 3. Predictive value of the Drought Tolerance Index (DTI) for field drought tolerance. DTI showed a good correlation with field experiments

A - Drought sensitive; B - Drought tolerant breeds 
this parameter. Drought tolerance index can be used for the preselection of breeding lines; for example, seedlings requiring extremely water intensive growth conditions can be eliminated early, thus reducing expenses and saving time. Moreover, this parameter can also be used for the characterization of drought tolerance and environmental requirements of already cultivated barley varieties.

Acknowledgement. We thank the reviewers' valuable suggestions on the first version of the manuscript. This study was supported by TÁMOP4.2.2 grant (a joint Hungarian and European Union project supporting basic and applied research). The publication is supported by the EFOP-3.6.3VEKOP-16-2017-00008 project. The project is co-financed by the European Union and the European Social Fund.

\section{REFERENCES}

ANJUM, S.A. - XIE, X. - WANG, L. - SALEEM, M.F. MAN, C. - LEI, W. 2011. Morphological, physiological and biochemical responses of plants to drought stress. In African Journal of Agricultural Research, vol. 6, no. 9, pp. 2026-2032. DOI: 10.5897/AJAR10.027

ASHRAF, M. 2010. Inducing drought tolerance in plants: recent advances. In Biotechnology Advances, vol. 28, no. 1, pp. 169-183. DOI: 10.1016/j.biotechadv.2009.11.005

CHAVES, M. - MAROCO, J.P. - PEREIRA, J.S. 2003. Understanding plant responses to drought - from genes to the whole plant. In Functional Plant Biology, vol. 30, pp. 239-264. DOI: 10.1071/FP02076

CONE, A.E. - SLAFER, G.A. - HALLORAN, G.M. 1995. Effects of moisture stress on leaf appearance, tillering and other aspects of development in Triticum tauschii. In Euphytica, vol. 86, no. 1, pp. 55-64.

COOPER, M. - FOX, P.N. 1996. Environmental characterization based on probe and reference genotypes. In COOPER, M. - HAMMER, G.L. (Eds.). Plant Adaptation and Crop Improvement. Wallingford : CAB International, pp. 529547. ISBN-10: 0851991084

FLEURY, D. - JEFFERIES, S. - KUCHEL, H. - LANGRIDGE, P. 2010. Genetic and genomic tools to improve drought tolerance in wheat. In Journal of Experimental Botany, vol. 61 , no. 12 , pp. 3211-3222.
FRENSCH, J. 1997. Primary responses of root and leaf elongation to water deficits in the atmosphere and soil solution. In Journal of Experimental Botany, vol. 48, no. 310, pp. 985-999.

HAMAYUN, M. - KHAN, S.A. - SHINWARI, Z.K. - KHAN, A.L. - AHMAD, N. - LEE, I.J. 2010. Effect of polyethylene glycol induced drought stress on physio-hormonal attributes of soybean. In Pakistan Journal of Botany, vol. 42, no. 2, pp. 977-986.

HAMMER, Ø. - HARPER, D.A.T. - RYAN, P.D. 2001. PAST: Paleontological statistics software package for education and data analysis. In Palaeontologia Electronica, vol. 4, no. 1, art. 4, pp. 1-9.

LOBELL, D. - FIELD, C. 2007. Global scale climate-crop yield relationships and the impacts of recent warming. In Environmental Research Letters, vol. 2, no. 1, article number 014002. DOI: $10.1088 / 1748-9326 / 2 / 1 / 014002$

MUNNS, R. 2002. Comparative physiology of salt and water stress. In Plant Cell Environment, vol. 25, no. 2, pp. 239 250. DOI: 10.1046/j.0016-8025.2001.00808.x

PASSIOURA, J.B. 1988. Root signals control leaf expansion in wheat seedlings growing in drying soil. In Australian Journal of Plant Physiology, vol. 15, pp. 687-693.

PEI, Z.F. - MING, D.F. - LIU, D. - WAN, G.L. - GENG, X.X. - GONG, H.J. - ZHOU, W.J. 2010. Silicon improves the tolerance to water-deficit stress induced by polyethylene glycol in wheat (Triticum aestivum L.) seedlings. In Journal of Plant Growth Regulation, vol. 29, no. 1, pp. 106-111. DOI: $10.1007 / \mathrm{s} 00344-009-9120-9$

SAMARAH, N.H. 2005. Effects of drought stress on growth and yield of barley. In Agronomy for Sustainable Development, vol. 25, no. 1, pp. 145-149. DOI: 10.1051/agro:2004064

SKRIBANEK, A. - SCHMIDTHOFFER, I. - CSONTOS, P. 2016. Drought-induced changes in photosynthetic parameters of seedlings of 22 barley cultivars. In Botanikai Közlemények, vol. 103, no. 2, pp. 237-248. DOI: 10.17716/ BotKozlem.2016.103.2.237

STUBER, C.W. - POLACCO, M. - LYNN, M. Senior 1999. Synergy of empirical breeding, marker-assisted selection, and genomics to increase crop yield potential. In Crop Science, vol. 39, pp. 1571-1583.

SCHACHTMAN, D.P. - GOODGER, J.Q.D. 2008. Chemical root to shoot signaling under drought. In Trends in Plant Science, vol. 13, no. 6, pp. 281-287. DOI: 10.1016/j. tplants.2008.04.003

TOMCSÁNYI, A. 2012. Spring barley post-registration variety trials 2011. In Agrofórum, vol. 2012, no. 2, http://regihonlap.agroforum.hu/archivum/agroforum-2012-februar

Received: February 20, 2018 